\title{
Uma realidade revisitada em tempos de Zika vírus e microcefalia: Estamos preparados para comunicar um diagnóstico de deficiência?
}

$\mathrm{R}$ ecentemente, o Ministério da Saúde (MS) confirmou a associação entre a infecção de gestantes pelo Zika vírus e os casos de microcefalia no nordeste brasileiro. Trata-se de uma emergência para a saúde pública do país, como foi reconhecido pelo próprio MS.

Desde então, diversas ações de enfrentamento da doença vêm sendo adotadas, as quais estão contidas: no Plano de Enfrentamento à Microcefalia, no Protocolo de Vigilância e Resposta à Ocorrência de Microcefalia Relacionada à Infecção pelo Vírus Zika, no Protocolo de Atenção à Saúde e Respostas à Ocorrência de Microcefalia Relacionada à Infecção pelo vírus Zika, dentre outras estratégias adotadas pelo MS. No entanto, algumas incertezas ainda pairam sobre a efetividade e o real tamanho de efeito que tais medidas terão na contenção do avanço da doença.

Neste cenário, abre-se espaço para a discussão de uma enorme gama de tópicos correlatos, tais como: o combate ao mosquito transmissor, o Aedes aegypti; a susceptibilidade imune da população brasileira à infecção pelo Zika, já que se trata de um vírus novo no país; os efeitos da infecção pelo Zika no sistema nervoso central; a possibilidade (ou a impossibilidade) do desenvolvimento de vacinas e/ou fármacos que previnam ou revertam o desenvolvimento da microcefalia e afins.

Por outro lado, este cenário também traz à tona uma discussão deveras importante: a comunicação do diagnóstico de uma doença e/ou condição de deficiência de bebês aos pais. Estamos preparados para fazê-lo? Quem deve ser o responsável pela comunicação? Como os profissionais da saúde enxergam a si mesmos neste processo? Como podemos auxiliar as pessoas na ressignificação de uma realidade não desejada? Como atuar na facilitação do processo de empoderamento dos pais e/ou familiares, com vistas à construção de uma rede pessoal significativa capaz de atender às necessidades de uma criança com deficiência? Como familiares e profissionais da saúde encaram as frustrações de um longo e, muitas vezes, limitado processo de reabilitação?

Algumas destas questões estão contidas em um dos estudos publicados nesta edição da Revista Ciência \& Saúde, nos possibilitando uma reflexão sobre tal temática que, independentemente dos "fatores etiológicos", revela-se sempre atual e necessária!

Boa leitura!

Régis Gemerasca Mestriner Doutor. Professor do curso de Fisioterapia da FAENFI-PUCRS 